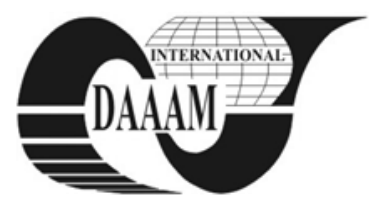

Annals of DAAAM for 2011 \& Proceedings of the 22nd International DAAAM Symposium, Volume 22, No. 1, ISSN 1726-9679 ISBN 978-3-901509-83-4, Editor B. Katalinic, Published by DAAAM International, Vienna, Austria, EU, 2011 Make Harmony between Technology and Nature, and Your Mind will Fly Free as a Bird Annals \& Proceedings of DAAAM International 2011

\title{
APPLYING THE CMMI MODEL IN SOFTWARE PROCESS IMPROVEMENT
}

\author{
KOZINA, M[elita]
}

\begin{abstract}
SPI (Software Process Improvement) methodology has its own history and increasingly applied for the improvement of the software development. CMMI (Capability Maturity Model Integration) and SPICE (ISO/IEC 15504) are important SPI models in today's practice. The purpose of the paper is to analyze the CMMI model and to conduct the assessment using this model for the software organization. The conducted research in the paper evaluates the target level of the organization maturity 2 (Managed). The obtained results show that the software organization has maturity level 1 (Initial) and achieves its business goals based on the processes that are not well managed. The management has to define the improvement needs and select the processes for the improvement.
\end{abstract}

Key words: software crisis, SPI methodology, CMMI model, assessment of the organization maturity level using CMMI.

\section{INTRODUCTION}

Many studies have shown a low level of IT project success and their results indicate the crisis in software development (for example-Standih Chaos Report). High costs, low productivity of development teams and low usability are the main features of the software product.

Software Engineering Institute (SEI) at Carnegie Mellon University in Pittsburgh, USA, began the development of a process improvement approaches and models for software engineering in the early 1980s. Capability Maturity Model for Software (SW-CMM) was the first their model. In addition, the Systems Engineering Capability Maturity Model (SE-CMM) was developed as well as the other CMM models. Each model had different approaches and methods for assessment (Chrissis, Konrad, Shrum, 2003). The aim was to integrate such models and make a CMMI model for integrated product and process development. Including CMMI, SPI (Software Process Improvement) methodology also includes models such as Bootstrap, Bootcheck, Trillium, SPICE (ISO/IEC 15504), etc.

Chapter 2 describes the basic concept of the SPI methodology (including CMMI). The basic components of the CMMI model are described in the Chapter 3. Conducted assessment of the software organization maturity using the CMMI model is analyzed and described in the Chapter 4 . The conclusion of the paper includes main benefits of SPI methodology as well as the problems related to their implementation through the enterprise. The purpose of the paper is to analyze one of the important SPI model, CMMI model and its application for the assessment of the software organization maturity.

\section{SPI CONCEPT}

According to the objectives of SPI, the process must be predictable, under statistical control and should be continuously improved. The life cycle of process improvement includes assessment of the current level of process capability, determining the target level of process capability, prioritization of the process improvement, as well as the implementation, monitoring and evaluation of these improvements. The process improvement life cycle is shown on Fig. 1 (Wysocki, 2004).

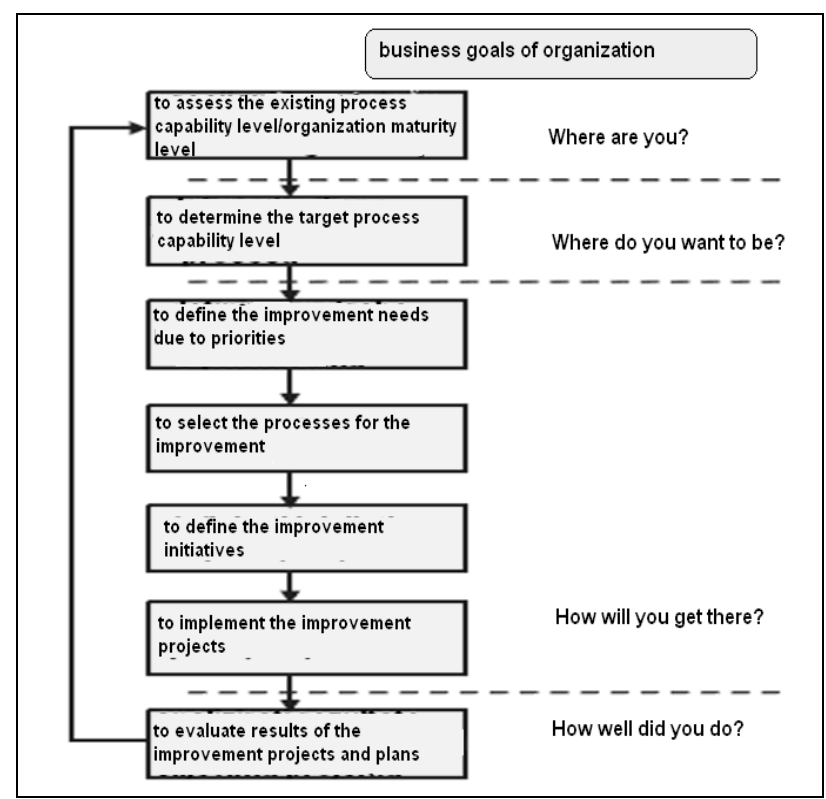

Fig.1. The process improvement life cycle

The concept of the SPI models are based on the two dimensional reference model for describing processes and process capability used in a process assessment. ISO/IEC 15504-2 defined this reference model. CMMI model is compatible with the requirements related to this model. The reference model defines a set of processes (key process areas) defined in terms of their domain, purpose, outcomes -process reference model, and a measurement framework for evaluating the capability of the processes through capability levels $(0=$ incomplete $; \quad 1=$ performed; $\quad 2=$ managed; $\quad 3=$ defined; $4=$ quantitative managed; $5=$ optimizing). This reference model is shown on Fig.2 (Sassenburg, Kitson, 2006).

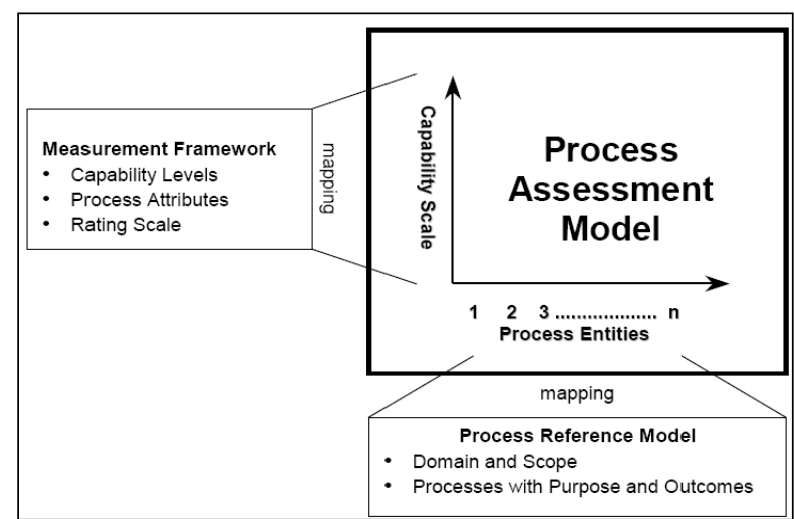

Fig.2. The reference model for the process assessment 


\section{CMMI STRUCTURE}

CMMI model has its structure based on the several important components (CMMI Product Team,2006). According to these components, the assessment of the capability level for the process area in the software organization, as well as the assessment of the maturity level of the whole organization are conducted and analyzed in the paper.

Each process area has its defined purpose. In addition, the goal (specific/generic) is the required outcome/achievement which is achieved by implementing effective practices (specific/generic).The practice describes the activities that are important for the implementation of the objectives (goals). Work products are the results of the specific practice (typical work products) as well as the results of the generic practice. These products are the important indicators for the assessment of the implementation the practices and achieving the goals. It may be different files, products, specifications, documents, etc.

\section{ASSESSMENT OF THE ORGANIZATION MATURITY LEVEL USING CMMI}

For the practical assessment in the paper, CMMI for Development (CMMI-DEV V1.2) was selected and its support tools - Appraisal Assistant Beta 3 (version 2.0.9). The process areas are organized by maturity level 2, 3, 4 and 5 (shown in Fig.4). The conducted research in the paper evaluates the target level of the organization maturity 2 (Managed). Accordingly, it is necessary to first conduct an assessment for the 7 key process areas organized by maturity level 2 (shown in Fig.4). The research method is mainly based on the interviews with the process owners and their documentation (work products as the main assessment indicators). Incomplete documentation and largely subjective responses were the main limitations of this research method.

The example of the practical capability level assessment for the one of seven process areas is shown on Fig.3. This is the assessment for the Requirements Management (REQM).

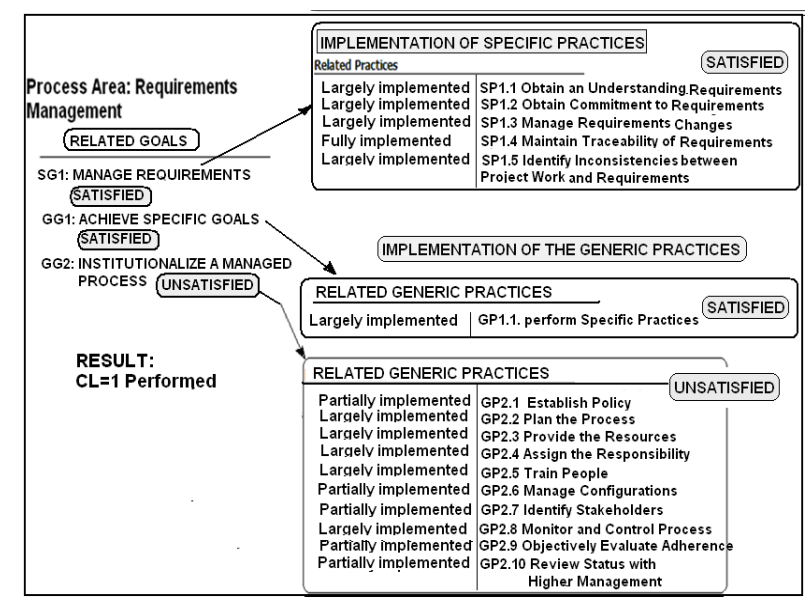

Fig.3. The assessment of the capability level (CL) for REQM (source: Author)

First, the assessment was conducted on the implementation specific practices based on the assessment indicators (different work products) according to the rating scale: fully implemented (80-100\%); largely implemented (50-80\%); partially implemented (20-50\%); not implemented (0-20\%); not yet $(0 \%)$. In addition, the assessment was made in order to assess the achievement of the specific goals for selected process area according to the rating scale: satisfied or unsatisfied. Same assessment procedure was conducted for the generic goals and practices. The assessment results of the REQM indicate that the capability level of the process is CL1 (Performed), not CL2.
Same assessment procedure was conducted for the other six process area organized by maturity level 2 in the software organization (shown in Fig.4). Some of them have the capability level 0 i.e. uncompleted process area (for example, configuration management). It is not enough for the organization maturity level 2 . The obtained results show that the software organization has maturity level 1 (Initial) and achieves its business goals based on the processes that are not well managed. In addition, the other process areas organized by maturity level 3,4 and 5 in the software organization are also analyzed and assessed. In practice, the organization maturity level is mainly 2 (or 3 ). In this organization the management should first decide about the improvements related to the processes of maturity level 2 . Overall results are shown in Fig.4.

\begin{tabular}{|c|c|c|c|c|c|c|c|}
\hline Organization Unit Maturity Rating : & turity Rating :] & \multicolumn{2}{|c|}{- ML1 - Intial } & \multicolumn{4}{|l|}{$v$} \\
\hline \multicolumn{4}{|c|}{ CMMI Equivalent Staging Table } & \multicolumn{4}{|c|}{ the obtained results } \\
\hline Model & Process Area & Acronym & ML & \begin{tabular}{l|l} 
CL1 & CL2
\end{tabular} & cL3 & CL4 & CL5 \\
\hline CMMI-Dev 1.2 & PROJECT MONITORING AND CONTROL & PMC & 2 & 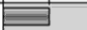 & & & \\
\hline CMMI-Dev 1.2 & PROJECT PLANNING & pp & 2 & 埚 & & & \\
\hline CMMI-Dev 1.2 & SUPPLIER AGREEMENT MANAGEMENT & SAM & 2 & & & & \\
\hline CMMI-Dev 1.2 & REQUIREMENTS MANAGEMENT & REQM & 2 & 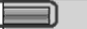 & & & \\
\hline Commi-Deviniz & $\begin{array}{l}\text { CONFIGURATION MANAGEMENT } \\
\text { MEASUREMENT AND ANALYSIS }\end{array}$ & $\begin{array}{l}\text { CM } \\
\text { MA }\end{array}$ & 2 & $\square^{\text {ML2 }}$ & & & \\
\hline CMMIDev 1.2 & PROCESS AND PRODUCT QUALITY ASS... & PPQA & 2 & 正 & & & \\
\hline CMMI-Dev 1.2 & ORGANIZATIONAL PROCESS DEFINITIO... & OPD & 3 & 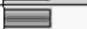 & & & \\
\hline CMMI-Dev 1.2 & ORGANIZATIONAL PROCESS FOCUS & OPF & 3 & 器 & & & \\
\hline CMMI-Dev 1.2 & ORGANIZATIONAL TRAINING & от & 3 & 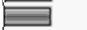 & & & \\
\hline CMMI-Dev 1.2 & INTEGRATED PROJECT MANAGEMENT ... & IPM & 3 & & & & \\
\hline CMMI-Dev 1.2 & RISK MANAGEMENT & RSKM & 3 & IVILJ & & & \\
\hline CMMI-Dev 1.2 & PRODUCT INTEGRATION & PI & 3 & & & & \\
\hline CMMI-Dev 1.2 & REQUIREMENTS DEVELOPMENT & RD & 3 & $\Longrightarrow$ & & & \\
\hline CMMI-Dev 1.2 & TECHNICAL SOLUTION & TS & 3 & & & & \\
\hline CMMI-Dev 1.2 & VALDATION & VAL & 3 & & & & \\
\hline CMMI-Dev 1.2 & VERIFICATION & VER & 3 & 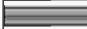 & & & \\
\hline CMMI-Dev 1.2 & DECISION ANALYSIS AND RESOLUTION & DAR & 3 & & & & \\
\hline CMMI-Dev 1.2 & ORGANIZATIONAL PROCESS PERFORMA.. & OPP & 4 & & & & \\
\hline CMMI-Dev 1.2 & QUANTITATIVE PROJECT MANAGEMENT & QPM & 4 & ML4 & & & \\
\hline CMMI-Dev 1.2 & ORGANZZATIONAL IINNOVATION AND D... & OID & 5 & ML5 & & & \\
\hline CMMI-Dev 1.2 & CAUSAL ANALYSIS AND RESOLUTION & CAR & 5 & & & & \\
\hline
\end{tabular}

Fig.4. The assessment of the target maturity level 2 for the software organization (source: Author)

\section{CONCLUSION}

Major SPI benefits include increased customer satisfaction, productivity, quality, cost savings, and cycle time reduction, ROI (Rico, 2004). SPI models can be combined with other methods and standards such as Six Sigma, statistical process control, ISO/IEC 9000; ITIL, ISO/IEC 20000, ISO/IEC 12207, ISO/IEC 15288, etc. The planning and implementation of the best practice according to CMMI (SPI) models is very expensive and complex task for the organization, especially for small businesses. It can take several years to move from level 1 to level 2. Moreover, whether the estimated maturity using CMMI or other SPI model really relevant indicator of business success in the market? Whether it is better to combine SPI with other quality standard? These are important questions for decision making within the organization.

\section{REFERENCES}

Chrissis, M.B., Konrad, M., Shrum, S.(2003). CMMI®: Guidelines for Process Integration and Product Improvement, Addison Wesley, Boston

CMMI Product Team (2006). CMMI for Development, Version 1.2,http://www.sei.cmu.edu/library/abstracts/reports/06tr0 08.cfm, Accessed: 2011-10-20

Rico, F.D.(2004). ROI of Software Process Improvement: Metrics for Project Managers and Software Engineers, J. Ross Publishing, Inc., U.S.A

Sassenburg H., Kitson D.(2006). A comparative analysis of CMMI and Automative SPICE, Carnegie Mellon University 